\title{
Natural Regeneration Practice in Degraded High Lands of Ethiopia Through Area Enclosure
}

\author{
Wondie Mebrat \\ Department of Biology, Adigrat University, Adigrat, Tigray, Ethiopia \\ Email address: \\ wondiemebrat@yahoo.com \\ To cite this article: \\ Wondie Mebrat. Natural Regeneration Practice in Degraded High Lands of Ethiopia Through Area Enclosure. International Journal of \\ Environmental Protection and Policy. Vol. 3, No. 5, 2015, pp. 120-123. doi: 10.11648/j.ijepp.20150305.11
}

\begin{abstract}
Forest provides livelihoods for millions of people worldwide through provision of different products. However, their diversity and area coverage are highly declined through time due to deforestation, invasive species, expansion of agricultural practice and land degradation. In line of these several interventions have been tried to undertake environmental degradation in Ethiopia. One of these intervention mechanisms is area enclosure, a method by which an area is protected from human and livestock interference. This method of environmental improvement appears to be successful, through applying artificial and natural regeneration methods. This method has indispensible role for rehabilitation of degraded lands, animal conservation, soil development and conservation. This paper is therefore helpful to know the success of conservation activities through enclosure and to design management plans for the future.
\end{abstract}

Keywords: Enclosure, Land Degradation, Natural Regeneration, Regeneration Methods

\section{Introduction}

Land degradation is the commonest environmental problem in Ethiopia. It is one of the major causes of low and declining agricultural productivity; continuing food insecurity and rural poverty. In addition, land degradation directly affected the type of plant grown on the area, reduced availability of potable water, lessened volumes of surface water, depletion of aquifers and biodiversity loss $[9,14,29$, 23]. It is also a severe problem resulted in natural capital asset depletion, drought, environmental and ecological imbalance. These activities have brought about changes in soil properties in the drainage basin adversely affecting farming output and the ecosystem in general [25]. Soil erosion, nutrient depletion and soil structural change are the main forms of land degradation observed in Ethiopia [9, 14]. This degradation resulted mainly through the conversion of natural vegetation to agricultural lands, unbalanced crop and livestock production, rapid population growth and settlement are also the main causes for this rapid deterioration of forest covered areas in Ethiopia $[6,7,17,26]$. The fate of those forests was ruthless exploitation and destruction, which in turn brought a severe reduction in biological diversity and ecological imbalance as well [1].Topography, soil types and agro-ecological parameters are also additional factors affecting the land degradation processes in the country influenced by human beings [23].

As a result of the above mentioned threats, woody species diversity is going to decline in a faster rate. Consequently, there was an urgent design management strategy and procedures practiced to safeguard remaining forests and recover degraded ones. Rehabilitation measures are required to restore some ecologically and economically valuable plant species diversity $[22,26]$. To combat this alarming degradation, it is important to design economically feasible, socially acceptable and ecologically viable management and conservation strategies for forest resources. Hence the purpose of this review is to address information about the practice of area closure and its success within a relatively short period of time in Ethiopia.

\section{Natural Forest Regeneration}

Literally, regeneration is rebirth, from which we get the phrase born again. In biology, an organism especially a plant is said to regenerate a lost part. Due to this the part re-grows and the original function is restored [15]. It is the process by which the forest is naturally renewed based on the recruitment of young plants derived from seeds (seedlings). Throughout their life cycle, forest species encounter different phases: characterized by intensive competition and high 
mortality; sapling stage with intensive height growth phase and mature tree characterized by canopy dominance [4]. The regeneration status of plant species is determined based on population size of seedlings and saplings [18]. It occurs naturally, without trees being planted. To regenerate naturally, the current forest must produce seedlings; stump sprouts, and root suckers that will become the next forest following harvest [11]. So, natural forest regeneration is the germination of native plants from seeds or propagules without human intervention, leading to self-sustaining plant populations. Regeneration of a species encompasses the production and dispersal of seeds, their germination and subsequently the growth of the juveniles until they reach maturity and start producing seeds themselves [5, 24]. This practice becomes successful by protecting degraded areas from external interference through enclosure is one of the mechanisms that facilitate natural regeneration. This is employed in situations where there are some trees left in the landscape to act as seed sources during secondary succession [16]. It involves deliberately managing of the land to enhance and accelerate the natural processes of ecological succession in order to re-establish a healthy and flexible enclosed forest ecosystem [2].

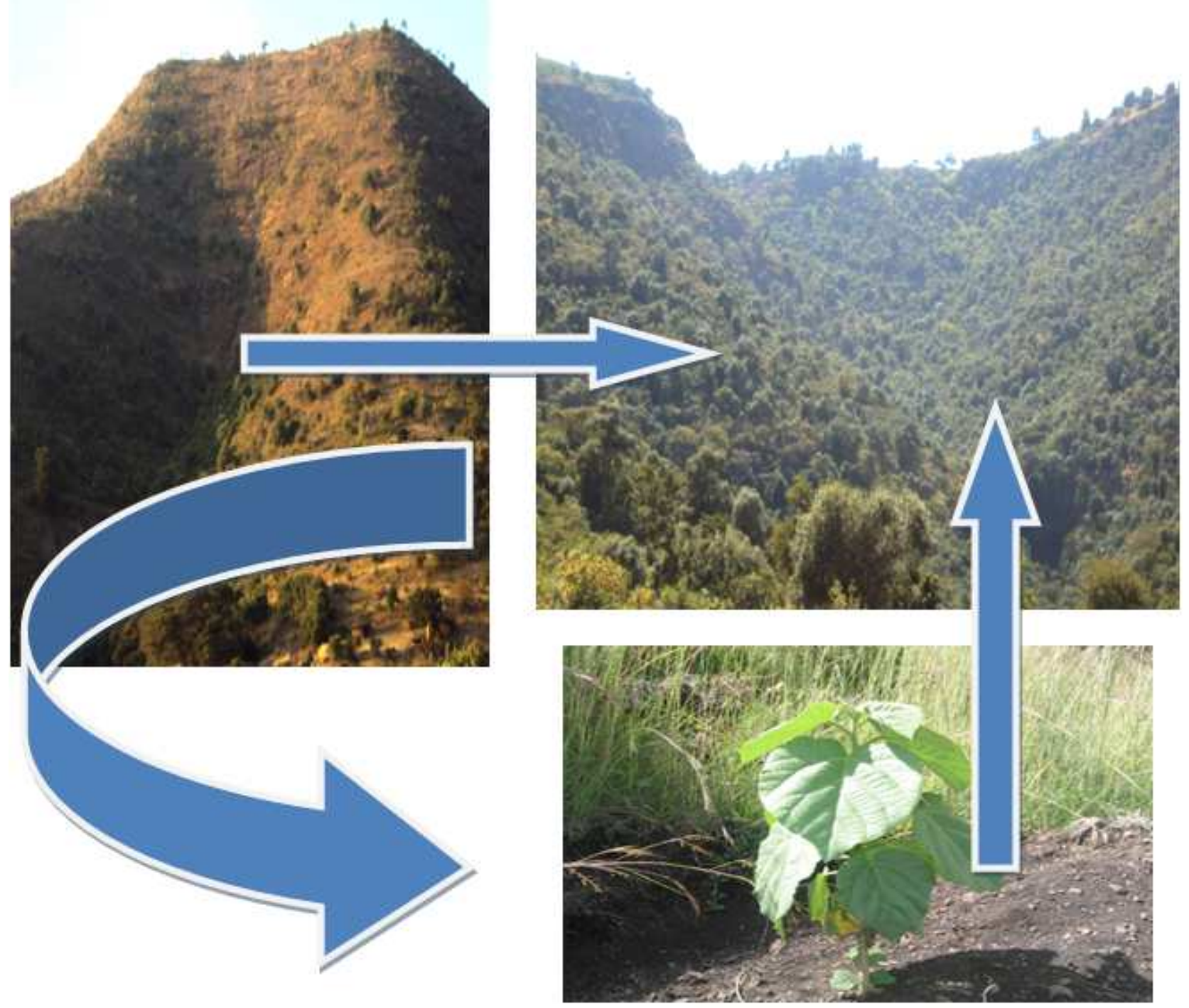

Figure 1. An illustration showing that any open site can be changed to dense forest through area enclosure and plantation (Photo by Author, 2015).

For instance, area enclosure is emerging as one of the strategies to rehabilitate and restore degraded environments [12]. It is the process of restoration and rehabilitation by natural means; however, the context and definition of area enclosure vary from country to country. According to $[3,26]$, area enclosure in the Ethiopian context is the protection of degraded land from human and livestock interference for rehabilitation. Primarily, human and animal interference is restricted in closure areas to encourage natural regeneration. As a result, rehabilitation of degraded lands through 
enclosure recently received attention in many parts of the Ethiopian especially northern and central highlands. Particularly in Tigray region alone a total of 262,000 ha have been enclosed so far, this figure included degraded lands which have some remaining forest species and forest land enclosed by the government. In the region no "Kebele" is found without enclosure(s). Likewise, in Amhara regional state many hectares of degraded lands rehabilitated though enclosures [3].

\section{Methods of Regeneration}

A regeneration method is a procedure by which a stand is established or renewed by means of natural or artificial reproduction. For this practice, two techniques of natural forest rehabilitations are under demonstration, namely: natural regeneration and aided regeneration. Natural regeneration involves protecting rehabilitation sites from external interference through enclosures. The technique is employed in situations where there are some trees left in the landscape to act as seed sources during secondary succession to facilitate natural regeneration. Aided regeneration on the other hand, involves planting indigenous tree species that have been identified to dominate the degraded sites during early stages of secondary forest succession. The trees planted are intended to act as nursery trees that provide shade, enrich the soil and the microhabitat for naturally recruiting woody species. The technique is employed in situations where deforestation has led to loss of seed sources and in areas where harsh site conditions are unfavorable for natural regeneration $[16,21]$.

Especially, aided natural regeneration (ANR) is an alternative approach for the regeneration of native woody plant species. It is used to accelerate regeneration by assisting the natural processes and involves cutting or pressing down the weeds around existing naturally occurring seedlings, protecting the site from fire and inter-planting with desired species if necessary [2]. It is a simple and lowcost forest restoration method that can effectively change degraded vegetation to more productive forests. The method aimed to accelerate, rather than replace, natural succession processes by removing or reducing barriers to natural forest regeneration such as soil degradation, competition with weedy species, and recurring disturbances (e.g., fire, grazing, and wood harvesting) [19].

As a result, these two regeneration methods are highly important for native plant species recovery. However, in most cases natural regeneration proves to be superior to aided regeneration. As seedlings derived from locally dispersed seeds are often better adapted to locally adverse environmental conditions; this is especially important at sites where trees are exposed to natural hazards over their entire life cycle [4]. These regeneration methods depend on the location, site index and discount rate. Considering the same genetic regeneration material, natural regeneration was the optimal method for most of the evaluated sites. However, planting was optimal only for stands of high site index and low rate of seedling mortality, which is associated with localities on low altitudes [21].

\section{Roles of Forest Regeneration}

Enclosure is the most valuable practice for returning native species to a degraded area. This results for rapid woody species restoration through area enclosures and it is an efficient measure for soil and water conservation, because of their capacity of infiltration and sediment trapping. This woody species coverage is chosen to be as the best alternative form of land use, not only to prevent the loss of soil minerals, stabilizing soil and reducing soil erosion, but also that it is not deposited in river bottoms, lakes and dams. It also played an important role in conserving remaining soil resources and improving soil fertility by adding soil nutrients from decomposed plant remains. This eventually improves the capability of the land to support other vegetation types, including exotic plantations and/or support livestock [8, 22].

As a result, many degraded lands are successfully colonized by native plant species in underline their potential in wasteland reclamation. In addition, the main contributions of area enclosures are provision of forest products including trees that can be used to the livelihoods of the rural poor through increasing incomes, improving food security, reducing vulnerability and enhancing well-being [8, 10, 13, 22]. Rehabilitation of the mountain area supports livelihoods by increasing productivity and biodiversity of fragile ecosystems. Furthermore establishment of area enclosure reduced the risks of flooding and drought in vulnerable ecosystems and improved land use planning of the watershed. Promotions of hillside enclosure establishments also help to enhance the sustainable utilization of agricultural land down streams [13].

\section{Conclusion}

Forests of Ethiopia are highly affected by several factors. Especially, expansion of agricultural activity, settlement, deforestation, land degradation and invasive species introduction are the main threats. As a result to minimize such threats, conservation of remnant forests and for further regeneration area enclosure is highly practiced in Ethiopia. It contributes to the rehabilitation of degraded areas within a short period of time through applying aided and natural regeneration methods. This practice is crucial to achieve the rehabilitation of vegetation cover and soil quality, while also contributes to improve livelihoods of life.

\section{References}

[1] Abiyou Tilahun, Hailu Terefe, Teshome Soromessa. The Contribution of Ethiopian Orthodox Tewahido Church in Forest Management and Its Best Practices to be Scaled up in North Shewa Zone of Amhara Region, Ethiopia. Agriculture, Forestry and Fisheries. Vol. 4, No. 3, 2015, pp. 123-137. doi: 10.11648/j.aff.20150403.18. 
[2] D. Blay, E. Bonkougou, S.A.O. Chanshama, and B. Chikamai, "Rehabilitation of degraded lands in Sub-Sahran Africa:" lessons learned from selected case studies. Forestry Research institute publisher, 2002.

[3] N. Betru, A. Jawad, and I. Nyborg, "Exploring ecological and socio-economic issues for the improvement of area enclosure management”. DCG report No. 38, 2005.

[4] M. Borghetti, and R. Giannini, "Natural regeneration in woodland management," biodiversity conservation and habitat management vol.1, 2001.

[5] T. Deml, "Seed and regeneration ecology in dry Afro mountain forests of Ethiopia" Forest disturbances and succession. Tropical Ecology, 46(1): 45-64, 2005.

[6] M. Eyayu, G. Heluf, M. Tekalign, and A. Mohammed, "Effects of land use changes on selected soil properties in the Tara Gedam Catchment and Adjacent Agro-Ecosystems". Ethiopian Journal of Natural Resources, 11(1): 35-62, 2009.

[7] FDRE (Federal Democratic Republic of Ethiopia), "National strategy and action plan for the implementation of the great wall institute in Ethiopia," 2012.

[8] FAO (Food and Agriculture Organization), "News and highlights: Forestry forum spotlights poverty alleviation." Rome, Italy, 2001.

[9] T. Genene and B. Wagayehu, "Farmers' perceptions of land degradation and determinants of food security at Bilate Watershed," Southern Ethiopia. EJAST 1(1): 49-62, 2010.

[10] A. Girma, K.A. Huss, and J. Tennigkeit, "Forest regeneration without planting: the case of community managed forest in the Bale Mountains of Ethiopia." Journal of the Dry Lands, 1(1): 26-34, 2006.

[11] D.R. Jackson, M.T. Wolf, and J.C. Finley, "Forest steward ship regenerating hard wood forests: managing competing plants, deer and light," College of agricultural science agricultural research cooperative extension Pennsylvania state university, 2009.

[12] M. Kibret, "Enclosure as a viable option for rehabilitation of degraded lands and biodiversity conservation." MSc. Thesis Kallu Woreda South Wello, Addis Ababa, 2008.

[13] G. Kindeya, "Dryland agro-forestry strategy for Ethiopia." Mekelle, Tigray, Ethiopia, 2004.

[14] D. Lakew, K. Menale, S. Benin, and J. Pender, "Land degradation and strategies for sustainable development in the Ethiopian highlands," Amhara Region, Amhara National Regional State Bureau of Agriculture. International Livestock Research Institute, Socio-economic and Policy Research Working Paper 32, 2000.

[15] I.K. Murthy, K.S. Murali, G.T. Hegde, P.R. Bhat, and N.H. Ravindranath, "Comparative analysis of regeneration in natural forests and joint forest management plantation." Current Science, Vol. 83: 1358-1364, 2002.

[16] J. Otuoma and M.O. Okech, "Demonstrating Techniques of Natural Forest Rehabilitation in Kakamega." Kibiri, Gwassi, Wire \& Homa Hills, Kenya Forestry Research Institute Maseno Regional Research Centre, 2009.

[17] S. Pant and S.S. Samant, "Assessment of plant diversity and prioritization of communities for conservation in mornaulareserve forests." G.B. plant institute of Himalaya environment and development. Himalaya unit, himachal Pradesh, India, 2007.

[18] P. Pokhriya, P. Uniyal, D.S. Challhan, and S. Todaria, "Regeneration status of tree species in forest of phakot and pathri Raowatersheds in garhwal Himalaya." Current Science, Vol. 98: No. 2, 2010.

[19] K. Shono, E.A. Cadaweng, and P.B. Durst, "Application of Assisted Natural Regeneration to Restore Degraded Tropical Forestlands." Restoration Ecology Vol. 15: No. 4, pp. 620 626, 2007.

[20] Silva, P. Jones, W. Eldridge, J. Thorpe, E. Campbell, and M. Ohara,. "Life and endangered plants, Conserving Europe's threatened flora," Published by Ethiopian communities, 2008.

[21] R. Simonsen, "Optimal regeneration method planting vs. natural regeneration of Scots pine in northern Sweden." Silva Fennica Vol. 47: no 2, 2013.

[22] M. Tefera, T. Demle, J. Kulten, and Y. Yelmshaw, "Role of in closed communities area Management in Ethiopia." Mountain Research and Development, 25(1): 44-50, 2005.

[23] G. Temesgen, B. Amare, and G.Hagos, "Land Degradation in Ethiopia: Causes, impacts and rehabilitation techniques." Journal of Environment and Earth Science, 4 (9): 98-104, 2014 .

[24] L.H. Vonulft, "Regeneration in Natural and Logged Tropical Rain forest," models seed dispersal regeneration of tropical trees in Guyana, tropenbos international publisher, 2004.

[25] Wabusya Moses, Humphrey Nyongesa, Martha Konje, Humphrey Agevi, Mugatsia Tsingalia. Effects of Land use Practices on Soil Organic Carbon, Nitrogen and Phosphorus in River Nzoia Drainage Basin, Kenya. Agriculture, Forestry and Fisheries. Vol. 4, No. 4, 2015, pp. 153-158. doi: 10.11648/j.aff.20150404.11.

[26] E. Winberg, "Participatory forest management in Ethiopia." Practices and experiences food and agriculture organization sub regional office for Eastern Africa, Addis Ababa, 2010.

[27] M. Zenebe, "A holistic approach to the restoration of degraded natural resources: A review and synthesis." Research Journal of Agricultural and Environmental Management Vol. 2(2), pp. 058-068, 2013. 